\title{
Design of the Optical Tomography System for Four Projections CMOS Linear Image Sensor
}

\author{
Norhafizah Ramli ${ }^{\mathrm{a}^{*}}$, Mariani Idroas ${ }^{\mathrm{b}}$, Muhammad Nasir Ibrahim $^{\mathrm{a}}$, Nur Hasanah Shafei ${ }^{\mathrm{a}}$ \\ ${ }^{a}$ Faculty of Electrical Engineering, Universiti Teknologi Malaysia, 81310 UTM Johor Bahru, Johor, Malaysia \\ ${ }^{b}$ Faculty of Petroleum and Renewable Energy Engineering, Universiti Teknologi Malaysia, 81310 UTM Johor Bahru, Johor, Malaysia
}

*Corresponding author: hafizah@fke.utm.my

\section{Article history}

Received :31 May 2012

Received in revised form :10

October 2012

Accepted :5 January 2013

Graphical abstract

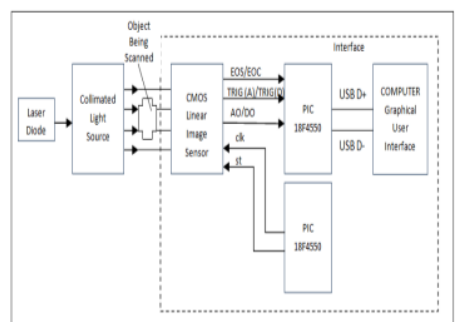

\begin{abstract}
The main purpose of this study is to design the optical tomography system for four projections complementary metal-oxide-semiconductor (CMOS) linear image sensor. This system includes the development of suitable driver for the operation of CMOS S10077 linear image sensor, measurement section and data acquisition system. The CMOS linear image sensor S10077 is configured around a flow pipe with an octagonal-shaped measurement section. This image sensor scans image of object inside the pipe from four different projections angle. When light hit the object, shadow will cast on the sensor surface. The output signal is obtained based on the light intensity projected to the sensor. Microcontroller PIC 18F4620 is used as a driver to enable the operation of CMOS linear image sensor and microcontroller PIC $18 \mathrm{~F} 458$ is used as a data acquisition circuit for optical tomography system. Microcontroller retrieves serial data from the CMOS linear image sensor and sends it to a PC for further work in image reconstruction.
\end{abstract}

Keywords: Optical tomography; image sensor; four projections CMOS linear image sensor

\begin{abstract}
Abstrak
Tujuan utama kajian ini adalah untuk mereka bentuk sistem tomographi optik untuk empat unjuran sensor garis gambar lelurus CMOS. Sistem ini melibatkan penghasilan pemacu yang sesuai untuk sensor garis gambar CMOS S10077 beroperasi, seksyen pengukuran dan sistem pengambil alihan data. CMOS sensor garis gambar dikonfigurasi di sekeliling paip aliran dengan seksyen pengukuran berbentuk oktagon. Sensor ini mengimbas imej objek di dalam paip dari empat sudut unjuran yang berbeza. Apabila cahaya dipancarkan kepada objek, bayangan akan terbentuk pada permukaan sensor. Isyarat output diperoleh berdasarkan keamatan cahaya yang diunjurkan kepada sensor itu. Mikropengawal PIC 18F4620 digunakan sebagai pemacu untuk mengaktifkan sensor garis gambar CMOS dan mikro pengawal PIC $18 \mathrm{~F} 458$ bertindak sebagai litar pengambil alihan data bagi sistem tomografi optik. Mikropengawal mendapatkan kembali data secara sesiri dari sensor garis gambar CMOS dan menghantarnya ke PC untuk kerja selajutnya dalam pembinaan semula imej.
\end{abstract}

Kata kunci: Tomography optik; sensor gambar; empat unjuran sensor garis gambar CMOS

(C) 2012 Penerbit UTM Press. All rights reserved.

\subsection{INTRODUCTION}

"Tomography" term originally derived from the Greek word in which 'tomos' to mean cut or divide while 'graphae' signifies that image, the sense of diagram or graphic presentation. ${ }^{1}$ Process tomography is a technique for measurement that involves the tomography imaging methods to obtain data from sensors. Process tomography provides several methods of obtaining the concentration profile of a process. One of the tomography fields that have become one of the vast growing technologies nowadays is optical tomography. Optical tomography involves studying a beam of light source (e.g. LED, infra-red, or halogen bulb) through a medium from one boundary point and detecting the level light received at another boundary using a sensor. ${ }^{2}$ The uses of tomography system are accounted in many types of processes and unit operation, including pipelines, stirred reactors, fluidized beds, and separators depending to the mechanism of sensor use. ${ }^{3}$

The goal of this study is to design an optical tomography system using CMOS linear image sensor. CMOS linear image sensor is the main component of this optical tomography system, used to sense the shadow of the particles inside the pipeline to produce image of the particle. ${ }^{4}$ Several research have been carried out in order to investigate the performance of process tomography of obtaining data from a pipeline. The number of sensor that are used and the projection technique applied in the study affect the accuracy of the data reading and image obtained. Parallel beam projection technique and less number of sensor used produced limited number of data obtained and may have a problem with 
beam convergence and aliasing effect. A research conducted by Mariani had proved that such problems can be minimized when four image sensors are configured around a flow pipe with an octagonal-shaped. ${ }^{5}$ This technique produces significant data to use for image reconstruction or particle characterizing.

This study presents a four projection, optical tomography system using CMOS as detector. Four CMOS linear image sensors are configured around a flow pipe with an octagonalshaped measurement section. The data acquisition system will be driven by a PIC microcontroller to retrieve all significant data while switching system using same PIC will control the operation of the four projections one by one mutually exclusive in order to avoid saturation the CMOS sensor from over exposure.

\subsection{PROBLEM STATEMENT}

Nowadays, many processes require the use of equipment like pipes and vessels as particle conveyor because of the structure of this type of equipment; it is difficult to detect what type of flow is inside them. Systems have to be developed whereby the controller is able to view objects within these pipes during its operation without interrupting the flow.

Application of tomography system by placing electronic sensors around a pipeline would enable measurements of activities inside the pipe which can be used for image reconstruction of whatever contained inside the pipe. The optical tomography system can only be performed in the presence of image sensor as a main component. Previous optical tomography using LED and optical fibers, cannot produce high resolution measurement due to the size of the sensors. ${ }^{6}$ In the same research field on optical tomography conducted by Mariani, CCD image sensor although promised high resolution image, it require external circuitry for data digitization with two power supplies. CMOS linear image sensor can offer more excellent imaging performance than that of CCD when it provides more on-chip circuit integration such as built-in analog to digital converters (ADCs) and much lower power consumption. ${ }^{7}$ However, the optimum performance of CMOS only can be achieved when the appropriate driver is supplied. Based on the previous work done by Foo, the accurate results cannot be obtained by using only one projections of image sensor. ${ }^{8}$ The extended into four projections, user can compare the data obtained from each projection. Besides, Data Acquisition System (DAS) is one of the basic Tomography systems hence if DAS system fails to operate, the displaying, scanning and storing the data for future work in image reconstruction or particle characterizing cannot be precede. Other than that, light source without precise control will affect the accuracy of the results because of CMOS sensor is very sensitive to the light.

\subsection{OPTICAL TOMOGRAPHY}

Process tomography consists of tomographic imaging of systems. In tomography, some physical quantity in the 3D distribution in the object is determined. ${ }^{9}$ A process pipe in industry is the common example of process tomography. There is a widespread need to get tomographic information about process. This information can be used, for example, in the design and control of processes. Tomography involves taking measurements around the periphery of an object (e.g. process vessel or patient) to determine what is going on inside. ${ }^{10}$

There are a few methods to conduct the tomography process. One of these methods includes the optical tomography. Compare to another method such as electrical capacitance tomography
(ECT) and ultrasonic tomography, optical tomography is an attractive method since it is non-intrusive in nature and safe as the transducer does not require direct physical contact with the flow. ${ }^{11,12}$

Hua Yan $(2010)^{13}$ reported that data obtained from the ECT system reflect medium distribution in a relatively large space due to its sensing field of ECT sensor non-uniformly distributed in a three-dimensional space. ${ }^{13}$ Hence, the image reconstruction quality obtained from ECT system was doubt. Monitoring system providing by ultrasonic tomography was able to reconstruct the distribution of a gas/liquid two-phase flow over the cross-section of a pipe while being non-invasive and possibly non-intrusive to the corresponding activities inside the column. ${ }^{14}$ However, ultrasonic sensor in most application cannot detect rough surfaced or foam covered fluids very well. It is highly vulnerable to damage when utilized for detecting the levels of acidic, alkaline, and organic compounds within a container.

The principle of an optical tomography system is to investigate the light attenuation level for each detector. It is conceptually straightforward and relatively low cost, has a better dynamic response and can be more portable for routine use in process plant. ${ }^{15}$

Optical tomography system is defines as a technique that enables one to determine the content of a close system without physically looking inside it. This application could improve manufacturing in industrial process that handling flow activities inside pipelines, stirred reactors, fluidized beds and also mixer because the flow inside can be determined without stopping the process.

\subsection{IMAGE SENSOR}

The main component in optical tomography system is its image sensor. Image sensor in easy way can be described as a device that converts the optical image to electrical signal. It will detect light intensity and convert into corresponding voltage value when it is exposed to different level of light intensity. ${ }^{8}$ The application of image sensor widely used in digital cameras, astronomical telescopes, scanners, video camcorders and other imaging devices.

There are two modern IC based optical image sensors that are widely used in optical tomography system, the charge-coupled devices (CCD) and complementary metal-oxide-semiconductor (CMOS) active-pixel sensor. Both CCD and CMOS imager are constructed from silicon. These give them fundamentally similar properties of sensitivity over the visible. Thus, both technologies provide the same ways in capturing light and convert incident light in term of photons into electronic charge by the same photo conversion process. Although CMOS chips sense light in the same way that a CCD does, CMOS sensors can be manufactured using the same process as that used to make many other processors and chips as the sensors use transistors and tiny wiring, as other processors do. This makes CMOS sensors often far cheaper than CCD.

\subsection{METHODOLOGY}

\subsection{Overall Concept of the Study}

This study contributed both parts hardware and software. Figure 1 shows the overall concept of this study which is a basic CMOS optical tomography system. Microcontroller and computer were interfaced using USB virtual COM port. The complete optical tomography system consists of a lighting system, measurement 
section, sensor system, data acquisition system, PIC microcontroller system, and image formation. Figure 2 shows an overview of the system.

The laser module used in this system produced red light at a wavelength of $600 \mathrm{~nm}$. Due to the safety factor and that CMOS sensor (S10077) is very sensitive to light, the laser module that operated at low power was chosen. The CMOS can be easily saturated if the light illuminating it was too bright.

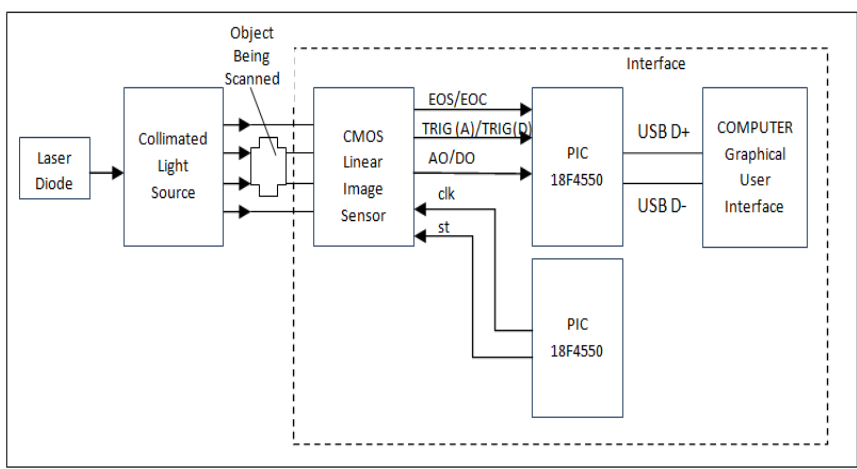

Figure 1 Overall concept of study

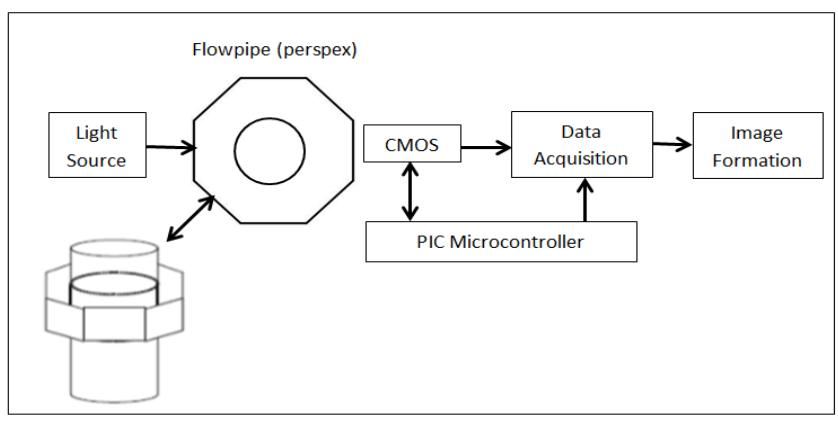

Figure 2 Block diagram of the optical tomography system

To control the operation of S10077 CMOS sensor operation, two microcontrollers, PIC18F458 and PIC 18F4620 were used in this study. The microcontroller PIC $18 \mathrm{~F} 4620$ provided clocking and start signal to CMOS sensor and another microcontroller PIC $16 \mathrm{~F} 458$ receive output from it at the same time for data acquisition. Data from CMOS image sensors was retrieved through the PIC microcontroller and recorded into computer data storage. Data was sent out serially from PIC.

\subsection{CMOS S10077 Linear Image Sensor}

CMOS linear image sensor, S10077 is a product from Hamamatsu Corporation. It is design for image input applications. ${ }^{16}$ The sensor is provided with on-chip switchable 8-bit/10-bit AD converter. This type of sensor can be applied in analytical instrument; position detection and image reading application. At the center of the CMOS IC surface is the active area which is the physical part of the sensor chip optical window where 1024 pixels location are located. Figure 3 shows the dimensional outline for S10077 CMOS linear image sensor which is called as active area that performs the actual computing and storage operations.

S10077 CMOS linear image sensor cannot perform without proper driver or configuration signals. The input signal which is clocking signal (clk) and start (st) signal should be provided to enable the operation of the sensor. The data sheet provide by the manufacturer state the clock pulse maximum frequency for 8-bit is $12 \mathrm{M} \mathrm{Hz}$ and the minimum frequency is $1 \mathrm{M} \mathrm{Hz}$. CMOS linear image sensor S10077 provide both type of output, digital and analog. Another electrical and optical characteristic of this sensor is that its spectral response range is between 400 to $1000 \mathrm{~nm}$ and the peak sensitivity wavelength is about $700 \mathrm{~nm}$.

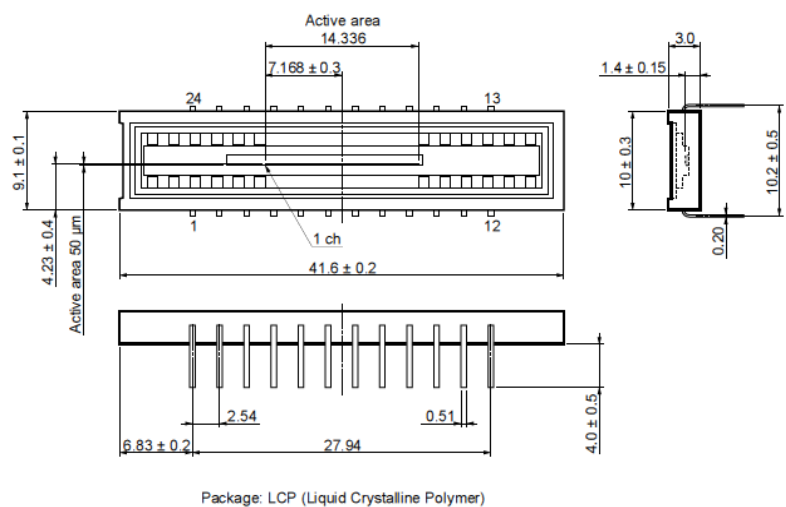

Figure 3 The dimensional outline for S10077 CMOS linear image sensor

\subsection{Experimental Setup}

The system is separated into three circuit boards - the S10077 CMOS sensor board, the PIC 18F4620 driver board, and the PIC 18F458 data acquisition board. The S10077 CMOS sensor board was connected to both PIC microcontrollers board. Figure 4 shows the experimental setup between S10077 CMOS sensor board and the two microcontroller boards.

Some precautions should be considered when dealing with S10077 CMOS linear image. Although this device has a built-in protection circuit against static electrical charges it is worthwhile to take counter measures such as grounding to prevent static discharges. For soldering task, it should be performed within 5 seconds at a soldering temperature below $260{ }^{\circ} \mathrm{C}$ to prevent excessive soldering temperatures and times. S10077 CMOS provide both digital and analog output. This study concerns on 8bits digital outputs. The sensor board built on the fabricated board was developed as shown in Figure 6. LED in this circuit board is used as power indicator. It will turn on when there is a power supply to the board.

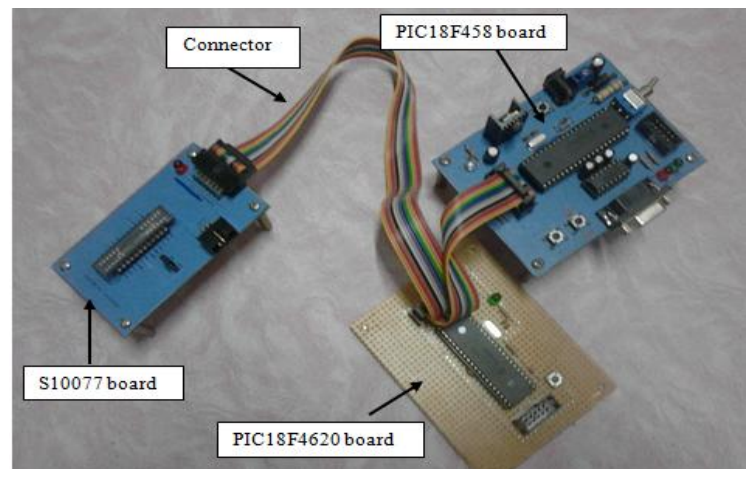

Figure 4 Connection between S10077 CMOS sensor board and microcontroller PIC18F4550 board 


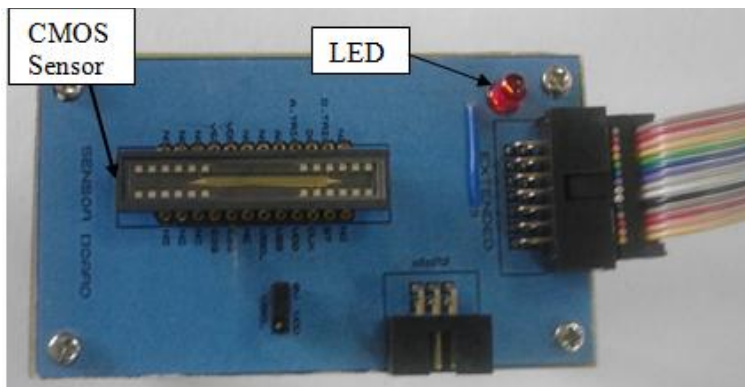

Figure 6 S10077 CMOS Linear Image Sensor Board

As mentioned earlier, two microcontrollers were used. The first one is microcontroller PIC 18F4620 used to provide the input signals to the sensor. This microcontroller needs to generate clock (clk) and start pulse signal (st) to the S10077 CMOS linear image sensor. Since this sensor performed operation at high frequency, the same microcontroller used to provide the input signals cannot be used to capture the data at the same time. Another microcontroller PIC 18F458 was introduced to read the strings of 8-bit serial data (1024 x 8-bit per line read) from the sensor and send it to the computer.

The prototype of the monitoring device was prepared for inspection of particle or object inside a pipe in industrial application. Figure 7 shows how the position of sensor placed in laser casing. Sensor is placed directly opposite to the laser source.

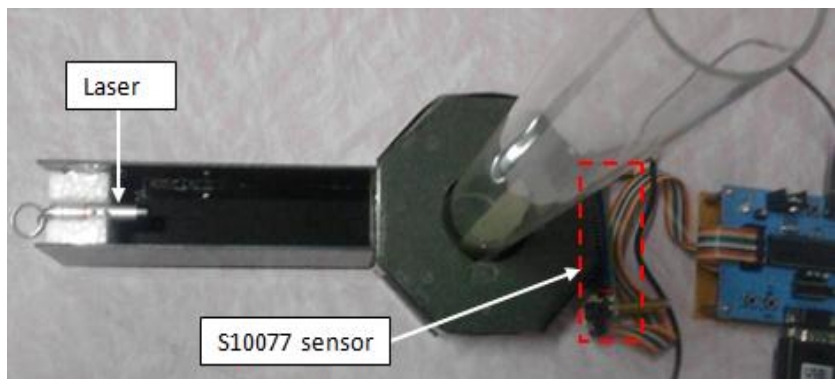

Figure 7 S10077 sensor and laser placed in prototype model

The measurement section in orthogonal shape was design in order to have four projections data. Various shape of object will be inserted in the pipe vessel and placed it in the middle of orthogonal measurement section. The pipe should be made of translucent material to avoid the light source being attenuated when there is no object inside. Figure 8 shows the experiment setup for optical tomography system for four projections CMOS linear image sensor.

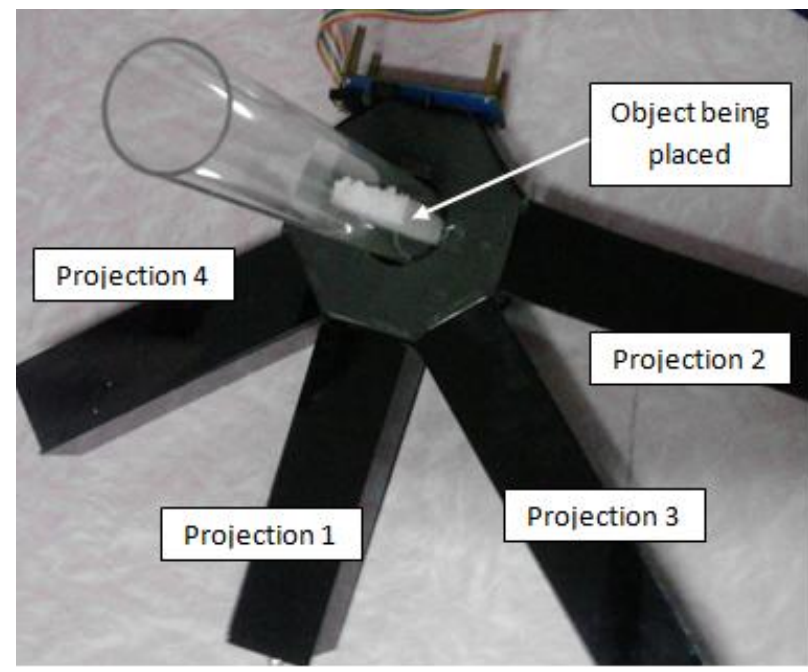

Figure 8 Experiment setup for four projection CMOS linear image sensor

\subsection{RESULTS AND DISCUSSION}

A number of experiments with various conditions of obstacles were tested to verify the performance of the system. The data from the experiments was analyzed and discussed. CMOS linear image sensor can operate by providing sensor with the clocking signal and start signal. Microcontroller PIC 18 F4620 is used to generate both signals to the sensor. The signal generated was initially observed using digital storage oscilloscope. These signals were compared to the (Clk and St) from the data sheet of S10077 CMOS linear image sensor. Figure 9(a) and Figure 9(b) showed the clock signal at $1.25 \mathrm{MHz}$ with nearly $50 \%$ duty cycle and the start pulse signal respectively that were successfully generated by the microcontroller PIC 18F4620.

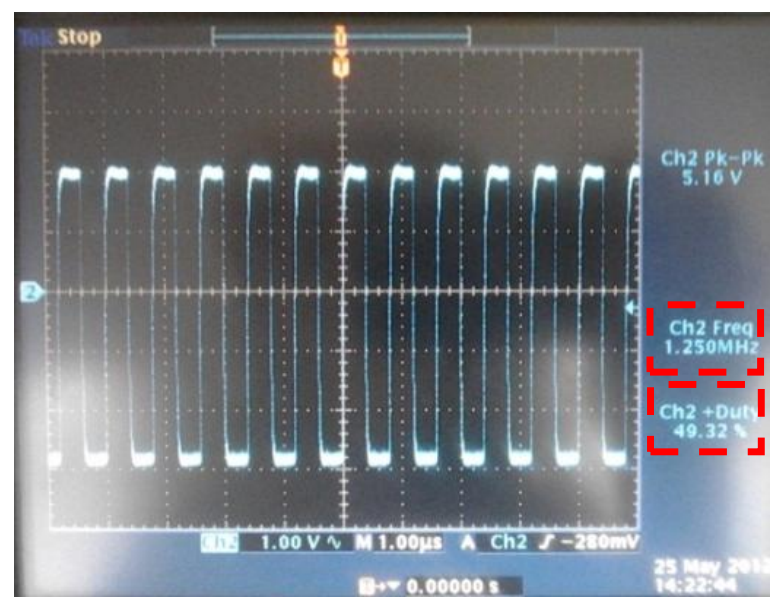

Figure 9(a) The clock signal 


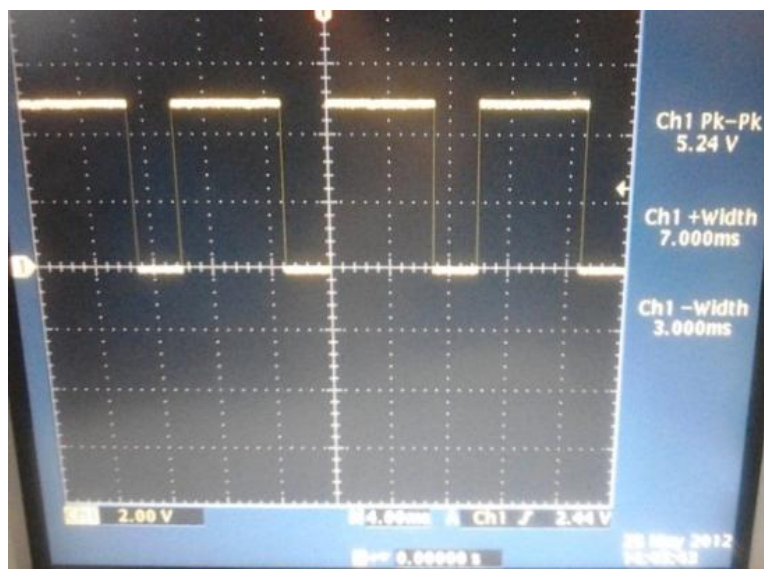

Figure 9(b) The start signal

The verification part for this system was done by testing the performance of the CMOS linear image sensor with four different conditions with projection one as the reference point of view. All experiments were conducted in controlled ambient light to allow high performance of the sensor and to avoid it from being saturated. The conditions included fully exposed, fully blocked, right part partially blocked, and left part partially blocked.

The result obtained from each cases testing for four projections of CMOS sensor were expressed in four separate graphs of pixel's intensity, 0 to 255 from 8 -bit pixel data, versus pixels number (1 to 1024) for each projection. Results for fully exposed and fully blocked are shown in Figure 10 and Figure 11 respectively. When there was no obstacle blocking the light path, all 1024 digital output (DO) data approaching to decimal 255 which is the maximum pixel value. There was no significant difference for data obtained from each projection since all projections experienced the same conditions. Apposite behavior obtained when CMOS sensor was fully blocked. Data from all four different projections were at low levels approaching to zero. This indicates the light that was directed to the sensor has been blocked by the object. Both of the result was correct as predicted. There are small fluctuations in the reading; this may be caused by some stray lights that were not well controlled during the experiments. Another two different conditions were carried out to further verify the functionality of the CMOS sensor where objects now partially block at different side of the pipe. Figure 12 is the result when the right side of the pipe was partially blocked referenced from projection 1. Pixels from number 553 to 1024 of projection 1 recorded low levels of intensity. This is consistent with the previous result where lower pixel values reflect the existence of object to the left of the pipe. Figure 13 on the other hand is the result when objects were switched to the left side of the pipe that caused blocking of the left side of the optical path. Now the low intensity level (or existence of objects) in projection 1 is detected at opposite side which around pixel 1 to 443 . This result confirmed that CMOS linear image sensor indeed working as expected.

The results for projection 2 for both conditions look similar to conditions when all pixels are fully blocked. This is actually true because projection 2 is viewing the pipe orthogonal to projection 1. This means when viewing from this angle, the objects would appear to incident with optical path coming from this direction and this resulted with high optical attenuation which in turn gives low pixel values. On the other hand, for projection 3 and 4 , these are sensors positioned diagonal to the pipe crosssection area. Most likely some small number of pixels near the edge of the pipe experienced similar to fully blocked conditions whereas the rest of the pixels experiencing moderately low blocking conditions such that the pixel values scattered around mid-point values between 0 and 255 . This explained the result obtained in graph projection 3 and 4 in Figure 12 and 13.
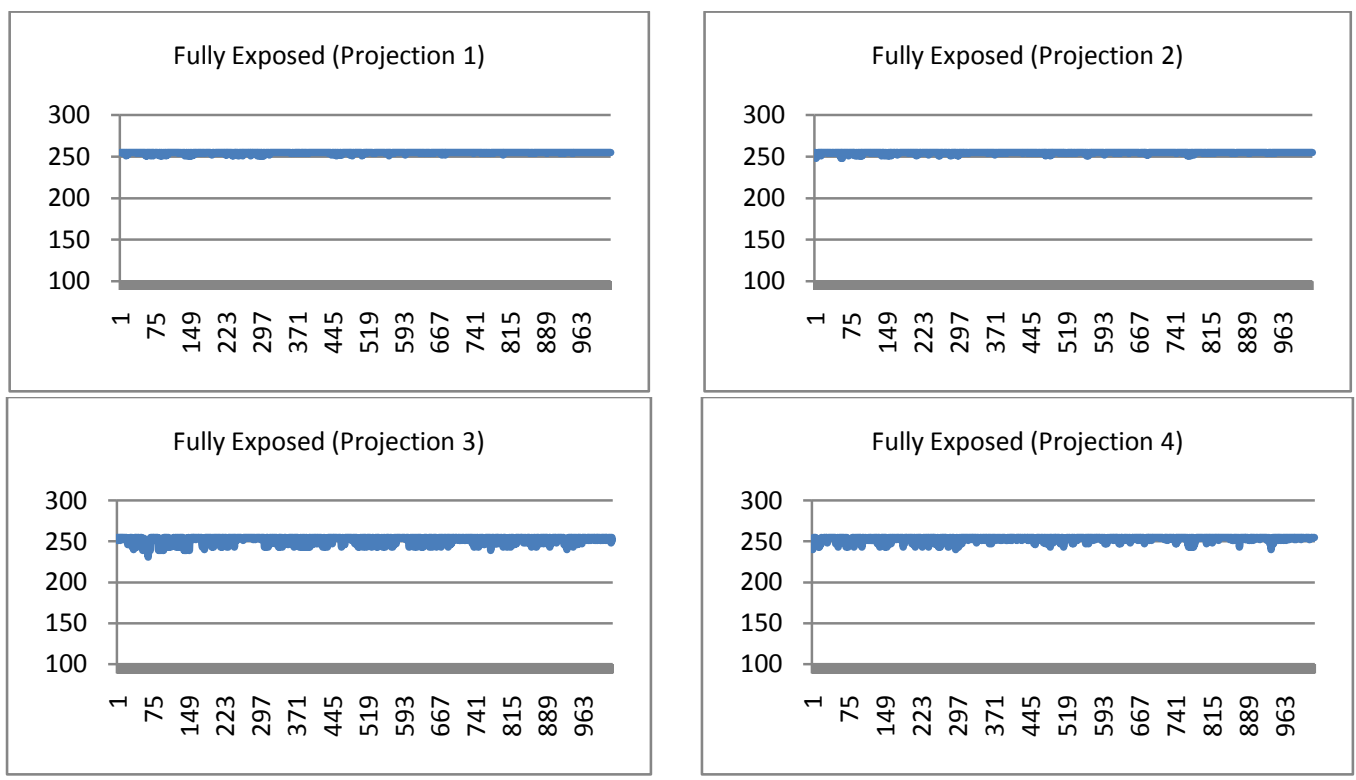

Figure 10 Result for fully exposed testing for four projections CMOS sensor 

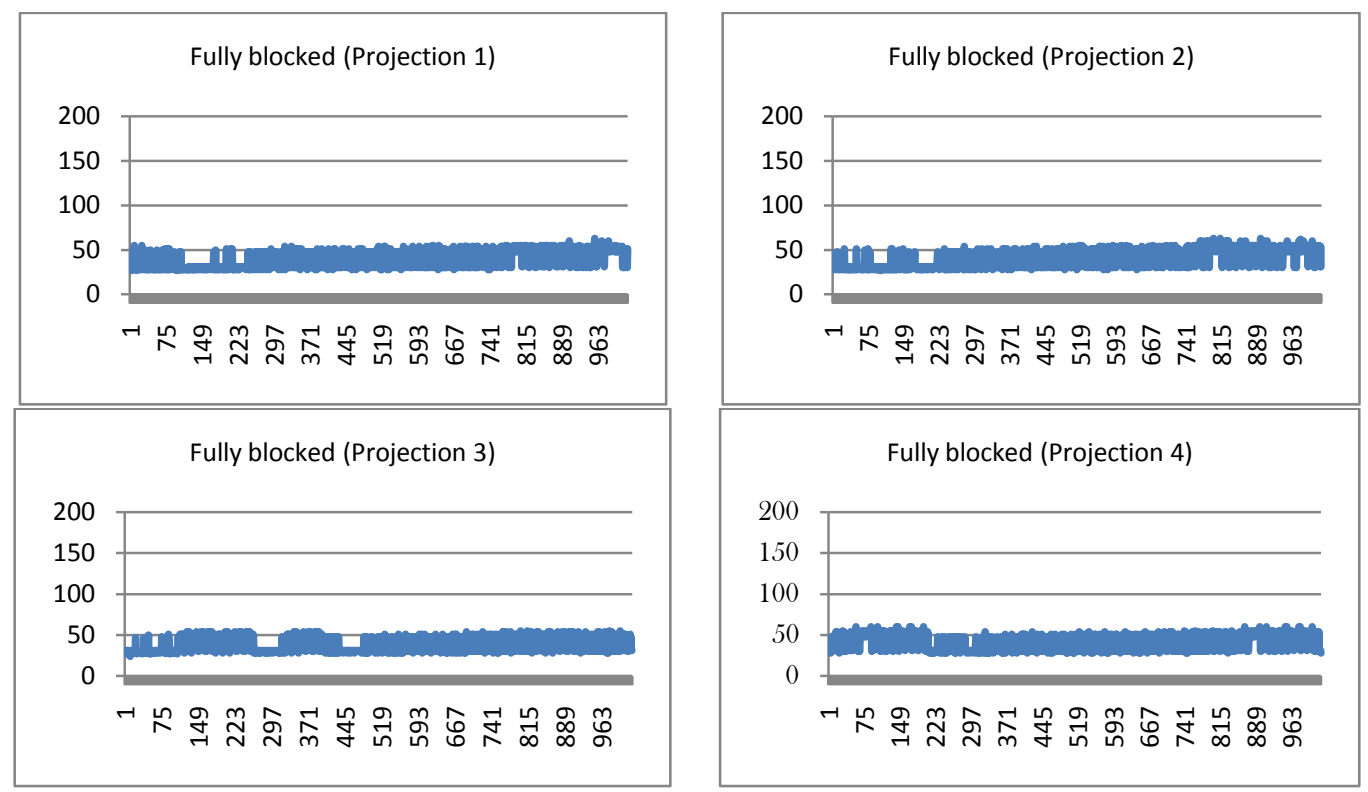

Figure 11 Result for fully blocked testing for four projections CMOS sensor
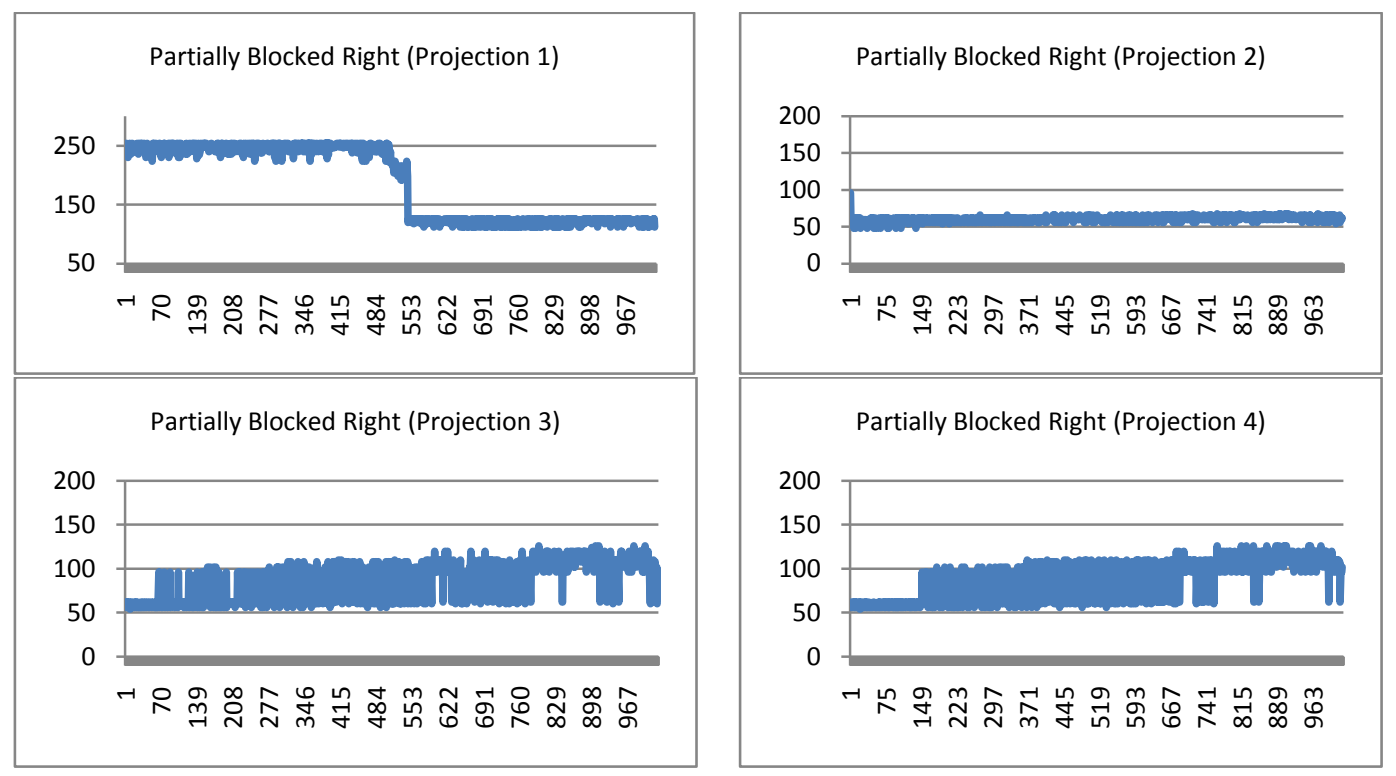

Figure 12 Result for partially right blocked testing for four projections CMOS sensor
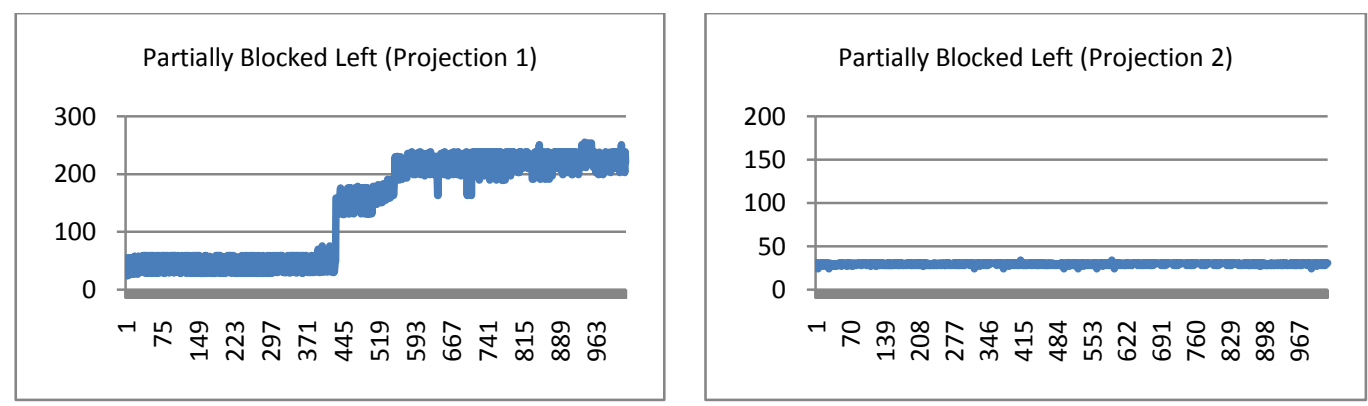

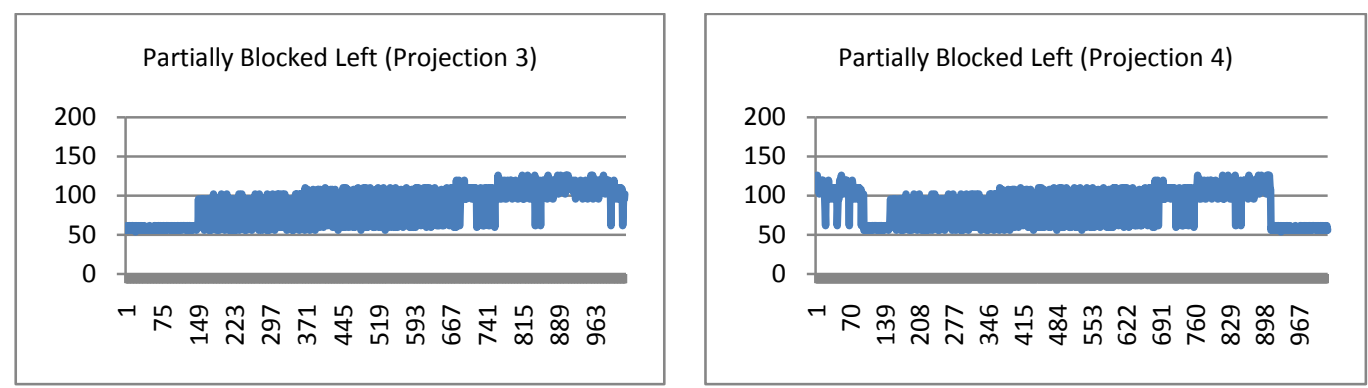

Figure 13 Result for partially left blocked testing for four projections CMOS sensor

To summarize, test and measurement were conducted for four projections under four different optical conditions. Low pixels value indicates lower optical intensity detected and high pixel values indicate high optical intensity or less hindrance along the optical path length. Graph plotted from first projection for partial block conditions indicates that sensor was able to differentiate whether left or right side was being blocked. Data from second projection for each case was minimum output because the sensor was blocked when taking measurement from this side. The results from projection three and four actually should be similar. The little bit difference may come from the reflection of the light inside the box and the casing.

\subsection{CONCLUSION}

The clocking signal and start pulse signal for the sensor were successfully generated by the microcontroller according to the minimum specifications which is the clocking signal not less than $1 \mathrm{M} \mathrm{Hz}$ and start signal low at the beginning and become high after stabilized. The interface system between the microcontroller and computer has been established using the USB COM port communication. All the data from four projections S10077 CMOS linear image sensor successful retrieved by the microcontroller and send to the computer. Digital output of the sensor is stored in Excel file for further research in image reconstruction. In conclusion, this system can be applied to detect shape of obstacle which blocks light from reaching sensor.

\section{Acknowledgement}

This paper is a part of a publication series on Research and Development in Signal, Image and Sensors in Biomedical Engineering Applications. The authors are indebted to Universiti Teknologi Malaysia for financial support.

\section{References}

[1] Patel, P. J., Chen, F. K. 2011. Intrasession Repeatability of Optical Coherence Tomography Measures in Active Neovascular Age-Related Macular Degeneration. Acta Ophthalmologica. 89(6): 526-532.

[2] Abdul Rahim, R. 1996. A Tomography Imaging System for Pneumatic Conveyors Using Optical Fibres. Sheffield Hallam University. Ph.D Thesis

[3] Rahmat, Mohd Fuaad and Ahmed Sabit, Hakilo. 2005. Flow Regime Identification and Concentration Distribution of Solid Particles Flow in Pipelines using Electrodynamics Tomography and Artificial Neural Networks. In: Proceeding of the 9th International Conference on Mechatronics Technology, 5-8 December 2005, Kuala Lumpur.

[4] Noor Hanis Izzuddin. 2010. Development of LabVIEW Based Data Acquisition for CMOS Linear Image Sensor Tomography System. FYP Thesis. Universiti Teknologi Malaysia.

[5] Idroas, M., Abdul Rahim, R. 2011. Optical Tomography System Based on Charge-coupled Device Linear Image Sensors: Particle Size Measurement. Sensors and Actuators B: Chemical. 156(2): 572-577.

[6] Abdul Rahim, R., Leong, L. C. 2005. Data Acquisition Process in Optical Tomography: Signal Sample and Hold Circuit. 1st International Conference on Computers, Communications, \& Signal Processing with Special Track on Biomedical Engineering.

[7] Yean, F. S. 2010. Development of Microcontroller Based Driver for CMOS Linear Image Sensor. Final Year Thesis. Universiti Teknologi Malaysia.

[8] York, T. 2001.Status of Electrical Tomography in Industrial Applications. Journal of Electronic Imaging. 10(3): 608-619.

[9] Soleimani, M. 2008. Computational Aspects of Low Frequency Electrical and Electromagnetic Tomography: A Review. International Journal of Numerical Analysis and Modeling. 5(3): 407-440.

[10] Olmos, A., Primicia, J. 2006. Influence of Shielding Arrangement on ECT Sensors. Sensors. 6(9): 1118-1127.

[11] Ruzairi Abdul Rahim, Ng Wei Nyap, Mohd Hafiz Fazalul Rahiman and Chan Kok San. 2007. Determination of Water and Oil Flow Composition Using Ultrasonic Tomography. ELEKTRIKA. Journal of Electrical Engineering, Universiti Teknologi Malaysia. 9(1): 19-23.

[12] Hua Yan, Xiukun Ning, Yifan Wang, Yinggang Zhou. 2010. Sensing Field Analysis of 3D Direct Capacitance Imaging Sensor. 2nd International Conference on Computer Engineering and Technology.

[13] Nor Muzakkir Nor Ayob, Mohd Hafiz Fazalul Rahiman, Sazali Yaacob, Ruzairi Abdul Rahim. 2009. Ultrasound Processing Circuitry for Ultrasonic Tomography. Proceedings of the International Conference on Man-Machine Systems.

[14] Mustafa Musbah Elmajri. 2008. A Tomography Imaging System Using Two Types Of Sensors. Master Thesis. Universiti Teknologi Malaysia. 